\title{
Analysis of risk factors leading to postoperative urethral stricture and bladder neck contracture following transurethral resection of prostate
}

\author{
Huang Tao ${ }^{1}$, Yu Yong Jiang ${ }^{2}$, Qi Jun ${ }^{2}$, Xu Ding ${ }^{2}$, Duan Liu Jian ${ }^{2}$, Ding Jie ${ }^{2}$, Zhu Yu Ping ${ }^{1}$ \\ ${ }^{1}$ Department of Urology, Anhui Provincial Hospital,Hefei, Anhui, China; ${ }^{2}$ Department of Urology, Xin Hua \\ Hospital Affiliated to Shanghai Jiao Tong University School of Medicine, Shanghai, China
}

\section{ABSTRACT}

Purpose: To determine risk factors of postoperative urethral stricture (US) and vesical neck contracture (BNC) after transurethral resection of prostate (TURP) from perioperative parameters.

Materials and Methods: 373 patients underwent TURP in a Chinese center for lower urinary tract symptoms suggestive of benign prostatic obstruction (LUTS/BPO), with their perioperative and follow-up clinical data being collected. Univariate analyses were used to determine variables which had correlation with the incidence of US and BNC before logistic regression being applied to find out independent risk factors.

Results: The median follow-up was 29.3 months with the incidence of US and BNC being $7.8 \%$ and 5.4\% respectively. Resection speed, reduction in hemoglobin $(\Delta \mathrm{Hb})$ and hematocrit $(\triangle \mathrm{HCT})$ levels, incidence of urethral mucosa rupture, re-catheterization and continuous infection had significant correlation with US, while PSA level, storage score, total prostate volume (TPV), transitional zone volume (TZV), transitional zone index (TZI), resection time and resected gland weight had significant correlation with BNC. Lower resection speed $(\mathrm{OR}=0.48)$, urethral mucosa rupture $(\mathrm{OR}=2.44)$ and continuous infection $(\mathrm{OR}=1.49)$ as well as higher storage score $(\mathrm{OR}=2.51)$ and lower TPV $(\mathrm{OR}=0.15)$ were found to be the independent risk factors of US and BNC respectively.

Conclusions: Lower resection speed, intraoperative urethral mucosa rupture and postoperative continuous infection were associated with a higher risk of US while severer storage phase symptom and smaller prostate size were associated with a higher risk of BNC after TURP.

\section{ARTICLE INFO}

\section{Key words:}

Prostatic Hyperplasia;

Transurethral Resection

of Prostate; Postoperative

Complications; Dysuria; Risk

Factors

Int Braz J Urol. 2016; 42: 302-11

Submitted for publication:

October 06, 2014

Accepted after revision:

January 28, 2015

\section{INTRODUCTION}

Been widely used since the 1970s, transurethral resection of prostate (TURP) has been the most popular treatment of lower urinary tract symptoms suggestive of benign prostatic obstruction (LUTS/BPO). In recent years, new endourologic procedures including photoselective va- porization of the prostate (PVP), holmium laser enucleation of the prostate (HoLEP), PVP with the green light laser, transurethral microwave thermotherapy (TUMT), transurethral needle ablation (TUNA), etc. have been applied and found to be safe and effective from relevant randomized controlled trials (RCT) (1-6). However, TURP is still the major surgical method in developing countries 
including China for its lower cost and favorable outcome.

Comparing with initial application, the mortality of TURP has declined remarkably. Also, incidence of complications has decreased on account of developments in both surgical experience and endoscopic devices (7). Postoperative dysuria is often caused by urethral stricture (US) and bladder neck contracture (BNC), the incidences of which were reported from 0.3 to $9.2 \%$ and 2.2 to $9.8 \%$ respectively, in contemporary literature (8-10). Dysuria can severely impair surgical efficacy and patient's life quality, sometimes leads to re-operation and even fatal complications. To current knowledge, US is induce by excessive scar formation which is mainly the result of intraoperative urethral mucosa injury and continuous inflammation while the mechanism of BNC formation has not yet been completely understood (7). Many factors have been verified to correlate with high risks of US or BNC including unmanaged preoperative infection, unsuitable diameters of resectoscope, long resection duration time and postoperative catheterization, etc. In present research, we aimed to investigate the influence of specific perioperative clinical parameters on the occurrences of US and BNC after TURP, further disclosing available risk factors and assessing their force of inducing US and BNC.

\section{MATERIALS AND METHODS}

\section{Preoperative data collection}

This was a prospective study approved by the ethical committee of Xin Hua Hospital in April 2007. Patients with LUTS/BPO who have entered the urology department of Xin Hua Hospital for surgical therapy were recruited initially from July 2007 to June 2012.

The enrolled subjects have had a standard medication of $\alpha$-adrenergic blockers (terazosin, doxazosin or tamsulosin) combined with $5 \alpha$-reductase inhibitors (finasteride or dutasteride) for at least 6 months before surgical therapeutic decision being made based on both clinical assessment and the patient's desire. Either obvious LUTS or recurrent complications including hematuria, infection, bladder calculus and urinary retention, etc. were found in all candidates. Exclusion criteria in preoperative phase included: (1) maximum flow rate $\left(Q_{\max }\right)$ more than $20 \mathrm{~mL} / \mathrm{s}$; (2) detrusor underactivity (DUA) defined as detrusor pressure at $\mathrm{Q}_{\max }\left(\mathrm{Pdet}_{\max }\right)$ of $<40 \mathrm{cmH} 20$ with $\mathrm{Q}_{\max }$ of $<15 \mathrm{~mL} / \mathrm{s}$ (11) secondary to neurogenic bladder dysfunction or other diseases; (3) history of prostatic and/or urethral surgery; (4) previous diagnosis or intraoperative detection of US or BNC; (5) prostatic or bladder malignancy. Eligible candidates were invited to join the research before signing informed consent. After being inquired with a detailed clinical history, LUTS/BPO related subjective symptom were measured by the International Prostate Symptoms Score (IPSS) system consisting of storage and voiding phase score and the quality-of-life (QoL) questionnaires. Objective tests were carried out routinely, including complete blood count, urea, creatinine, electrolytes, bleeding and clotting tests, prostate specific antigen (PSA) and urine analysis. Total prostate volume (TPV), transitional zone volume (TZV) and intravesical prostatic protrusion (IPP) were measured by transrectal ultrasound scan (TRUS, Sequoia 512; Siemens, Cologne, Germany) before transitional zone index (TZI) being calculated as TZV/ TPV. $Q_{\max }$, average flow rate (Qave), postvoid residual urine volume (PVR) and $P \operatorname{det} Q_{\max }$ were measured by urodynamics including free flowmetry, water filling cystometry and pressure flow study relying on a multichannel system (UDS64-III; Laborie, Quebec, Canada). Bladder outlet obstruction index (BOOI, by "PdetQ $Q_{\max }-2 Q_{\max }$ ") and the bladder contractility index (by "Pdet $Q_{\max }+5 Q_{\max }$ ") were calculated by equations from the ICS (12).

\section{Characteristics of surgery}

Standard procedure with technique of complete adenoma resection was given by a single surgical team including 3 doctors with over 5 year's TURP operation experience after formal training. Surgery were performed with the use of a 25.6 F continuous irrigation resectoscope (USA Elite System; GYRUS ACMI, Southborough, MA, USA) equipped with standard tungsten wire loop and monopolar energy (Valleylab Force FX, Boulder, CO, USA) settings for cutting and coagulation at $180 \mathrm{~W}$ and $70 \mathrm{~W}$ respectively. 5\% glucose solu- 
tion was used as flushing fluid, routine blood glucose monitoring and advanced circulatory loading measurement were applied during the surgery. 22F urethral triple-lumen Foley catheter was placed and continuous irrigation using sterile saline was applied if apparent hematuria occurred postoperatively. Catheter was conventionally removed 72 hours postoperatively after urine had been clear. Antibiotic prophylaxis was applied pre-and 12 hours postoperatively using second generation cephalosporin. Patients were prescribed oral third generation quinolones for two weeks postoperatively.

Resected tissue was squeezed and weighed in operation room immediately after completion of surgery. The real weight of resected gland was calculated as "resected tissue weight $\times 1.2$ ", due to dehydration by electroresection (13). Resection time and other details of surgery were also recorded. Blood loss was estimated by the reduction in hemoglobin $(\Delta \mathrm{Hb})$ and hematocrit $(\triangle \mathrm{HCT})$ levels before and 24 hours after surgery (14). Resection speed was calculated as tissue weight being divided by resection time. The incidence of intraoperative transfusion, capsule perforation and transurethral resection syndrome (TURS) were recorded.

\section{Postoperative and follow-up characteristics}

Duration of catheterization in hospital, incidence of re-catheterization (caused by serious hemorrhage or retention) and continuous infection (defined as positive urine test persisting over 6 weeks after removal of catheter) were recorded. Patients were asked to enter regular follow-up 3, $6,12,18,24$ and 36 months after surgery if no emergent complications such as haematuria, acute retention, symptomatic infection or incontinence, etc. has happened. During follow-up, patients were re-examined with assessment of IPSS, QoL, urine test and free flowmetry. US and BNC were highly suspected if patients complained of aggravating dysuria or $Q_{\max }$ less than $10 \mathrm{~mL} / \mathrm{s}$. Definite diagnosis was made by urethroscopy and urethrography.

\section{Statistical methods}

Perioperative and follow-up data of all subjects are listed in Tables-1 and 2. Patients were grouped according to the occurrence of US and BNC. Kolmogorov-Smirnov goodness-of-fit test was used to determine whether the distribution of a certain variable was normal. Because the number of enrolled variables is large and many variables have mutual correlation between each other, Student's t-test, Mann-Whitney U-test or chi-square test were firstly applied to select continuous or categorical variables significantly affecting the susceptibility to US or BNC (Table-3). The threshold of $\mathrm{P}$ value was set to 0.1 in order to avoid improper omission. Then, logistic regression analysis using stepwise forward method was carried out to filter variables from univariate analyses; likelihood ratio tests with a significance level of 0.05 were used to include or remove any of the factors at each step (Table-4). Finally, cut-off value of continuous variables selected from logistic regression was calculated by receiver operator characteristic (ROC) curve (Table-4). All calculation was processed using routines of the IBM SPSS ver. 19.0 (IBM Co., New York, NY, USA).

\section{RESULTS}

Primarily 407 patients have been enrolled. Nine and 7 patients were excluded because of post-surgery pathologically confirmed prostate and bladder cancer respectively, remaining 391 subjects with no intraoperative mortality. During follow-up period, 2 patients died due to reasons unrelated with prior surgery, 10 were lost to follow-up and 6 were unwilling or unable to participate; 373 remained available for long-term outcome review and contributing to the final analyses. All subjects with mean age of 64.1 years old have undergone TURP, and no seriously complication was observed. At the end of data collection, mean follow-up period was 29.3 months, consisting of 109, 138 and 126 patients with follow-up period over 12, 24 and 36 months respectively. US and BNC were diagnosed in 29 and 20 patients (including 5 patients having both complications) with mean diagnostic time of 2.2 and 3.7 months postoperatively.

Patients were stratified into different subgroups according to the occurrence of US or BNC. No preoperative factors were found to be signi- 
Table 1 - Baseline and follow-up data of 373 patients.

\begin{tabular}{|c|c|c|c|c|c|}
\hline \multirow[b]{2}{*}{ Variables } & \multirow[b]{2}{*}{ Baseline } & \multicolumn{3}{|c|}{ Follow-up } & \multirow[b]{2}{*}{ P-value ${ }^{* \star *}$} \\
\hline & & $\begin{array}{l}\text { 12 23 months } \\
(\mathrm{N}=109)\end{array}$ & $\begin{array}{l}24 \sim 35 \text { months } \\
(\mathrm{N}=138)\end{array}$ & $\begin{array}{c}36 \text { months } \\
(\mathrm{N}=126)\end{array}$ & \\
\hline Age (year) & $64.1 \pm 6.4$ & & & & \\
\hline Serum total PSA (ng/mL) & $5.5 \pm 2.1$ & & & & \\
\hline IPSS & $16.6 \pm 5.5$ & $5.0 \pm 2.9$ & $5.7 \pm 2.5$ & $6.3 \pm 2.4$ & $0.001^{*}$ \\
\hline Storage Score & $7.6 \pm 2.7$ & $4.5 \pm 1.6$ & $4.9 \pm 2.2$ & $5.1 \pm 2.9$ & $0.024^{*}$ \\
\hline Voiding Score & $7.2 \pm 2.1$ & $1.3 \pm 0.8$ & $1.2 \pm 0.6$ & $1.7 \pm 0.9$ & $0.011^{*}$ \\
\hline QoL index & $5(3,6)$ & $1(0,4)$ & $1.5(0,4)$ & $1(0,5)$ & $0.027^{\star *}$ \\
\hline \multicolumn{6}{|l|}{ Ultrasonography } \\
\hline TPV (mL) & $76.5 \pm 20.9$ & & & & \\
\hline TZV (mL) & $42.0 \pm 8.3$ & & & & \\
\hline TZI & $0.53 \pm 0.12$ & & & & \\
\hline IPP (mm) & $16.2 \pm 5.7$ & & & & \\
\hline \multicolumn{6}{|l|}{ Urodynamics } \\
\hline$Q_{\max }(\mathrm{mL} / \mathrm{s})$ & $6.1 \pm 2.1$ & $17.9 \pm 5.8$ & $16.6 \pm 7.0$ & $16.2 \pm 6.1$ & $0.006^{*}$ \\
\hline Qave (mL/s) & $3.6 \pm 1.1$ & & & & \\
\hline$P \operatorname{det} Q_{\max }$ & $77.9 \pm 16.6$ & & & & \\
\hline PVR (mL) & $69.7 \pm 25.4$ & & & & \\
\hline BOOI & $91.6 \pm 30.9$ & & & & \\
\hline $\mathrm{BCl}$ & $118.3 \pm 14.3$ & & & & \\
\hline
\end{tabular}

Values are presented as mean $\pm \mathrm{SD}$ or median (range).

PSA = total prostate-specific antigen; IPSS = International Prostate Symptom Score; $\mathbf{Q} \mathbf{0 L}=$ quality of life; $\mathbf{T P V}=$ total prostate volume; $\mathbf{T Z V}$ = transitional zone volume; $\mathbf{T Z I}=$ transitional zone index; IPP = intravesical prostatic protrusion; $\mathbf{Q}_{\max }=$ maximum urinary flow; $\mathbf{Q}$ ave = average urinary flow; $\mathbf{P}$ det $\mathbf{Q}_{\max }=$ pressure of detrusor at $\mathbf{Q}_{\max }$; $\mathbf{P V R}=$ postvoiding residual; $\mathbf{B O O} \mathbf{~ = ~ b l a d d e r ~ o u t l e t ~ o b s t r u c t i o n ~ i n d e x ; ~} \mathbf{B C} \mathbf{I}=$ bladder contractility index

*Student's t-test; * Mann-Whitney U-test; ***36 months' follow-up vs baseline.

ficantly different between patients with US or not from univariate analysis $(P>0.1)$, while some operative factors were found to have significant correlation with the occurrence of US and BNC $(\mathrm{P}<0.1$, Table-3). After the analysis of multivariate variables, urethral mucosa rupture and continuous infection were identified as final risk factors of US while higher storage score and lower TPV were found to correlate with higher incidence of BNC (Figures-1, 2 and 3).

\section{DISCUSSION}

LUTS/BPO is a common condition in aging male population. TURP has dominated surgical treatment of LUTS/BPO for over 70 years (15). With the innovation of medicines including $\alpha$-adrenergic blockers, $5 \alpha$-reductase inhibitors, plant medicines, etc. medication has become the first-line therapy of LUTS/BPO gradually, especially in most developed countries (16). However, 
Table 2 - Peri-operative data of 373 patients.

\begin{tabular}{lc}
\hline Variables & \\
Resection time (min) & $56.4 \pm 10.2$ \\
Resected gland weight $(\mathrm{g})$ & $47.3 \pm 8.7$ \\
Resection speed (g/min) & $0.82 \pm 0.11$ \\
$\Delta \mathrm{Hb}(\mathrm{g} / \mathrm{dL})$ & $-(1.6 \pm 0.24)$ \\
$\Delta \mathrm{HCT}(\%)$ & $-(6.0 \pm 2.3)$ \\
Incidence of urethral mucosa rupture & $48(12.9)$ \\
Incidence of capsule perforation & $36(9.7)$ \\
Incidence of TURS & $13(3.5)$ \\
Incidence of transfusion & $23(6.2)$ \\
Duration of catheterization in hospital (d) & $3(3,12)$ \\
Incidence of re-catheterization & $23(6.2)$ \\
Incidence of countinous infection & $31(8.3)$ \\
\hline
\end{tabular}

Values are presented as mean $\pm \mathrm{SD}$, median (range) or number (\%).

$\mathbf{H b}=$ hemoglobin; $\mathbf{H C T}=$ hematocrit; $\mathbf{T U R S}=$ transurethral resection syndrome.

TURP still plays an important role in LUTS/BPO patients either being refractory to medication or having severe complications in some developing countries.

High mortality of TURP was observed during the period of its initial use, which has been reported as $2.5 \%$ by Holtgreve et al. among 2.015 cases in 1962 (17). Fortunately, this value has decreased substantially during the past few decades to $0.25 \%$ in contemporary series (18), mainly attributable to the improvements of anesthesia and surgical procedure (19). Along with the development of safety, surgical efficacy and long-term outcome have also improved remarkably due to numerous technical progression including video-assisted system, continuous-flow instruments, special loop designs, modifications of high-frequency generators and appropriate perioperative medical treatment (20), thus making TURP one of the most common surgical methods worldwide and the "gold standard" in treating LUTS/BPO, with $>90 \%$ of the patients reporting normal or improved voiding after 10 year follow-up period (5, 21). Although certain minimally invasive and en- doscopic therapies including HoLEP, PVP, TUMT and TUNA have shown favorable short/long-term results, the "golden standard" status of TURP has not been threatened without cohort studies of large samples $(4,22-25)$.

As mentioned before, significant technical improvements of TURP have made a major impact on the incidence of associated morbidity. Therefore, the risk of intra/postoperative complication of contemporary TURP is lower than that reported previously (20). In addition to technical complications such as bleeding, capsule perforation, TURS, clot retention, urinary tract infection, hydronephrosis, urosepsis and incontinence, associated morbidity consisting of cardiac arrhythmia, myocardial infarction, pulmonary embolism, pneumonitis, chronic obstructive pulmonary disease (COPD) and deep vein thrombosis have been documented in $0.5 \%$ to $11 \%$ of patients postoperatively (26-29).

Another important postoperative long-term complication is failure to void, often caused by US or BNC. In former literature, US rate ranges from 2.2 to $9.8 \%$ while $\mathrm{BNC}$ from 0.3 to 
Table 3 - Data comparison of patients divided by the occurrence of US and BNC during follow-up.

\begin{tabular}{|c|c|c|c|}
\hline \multirow{2}{*}{ Parameters } & \multicolumn{3}{|c|}{ BNC } \\
\hline & With & Without & P-value \\
\hline$N(\%)$ & $20(5.4)$ & $353(94.6)$ & \\
\hline Serum total PSA (ng/mL) & $5.8 \pm 2.0$ & $3.6 \pm 1.3$ & $0.049^{*}$ \\
\hline IPSS & $18.6 \pm 4.1$ & $17.2 \pm 3.5$ & $0.340^{*}$ \\
\hline Storage Score & $10.3 \pm 1.9$ & $6.5 \pm 1.4$ & $0.042^{*}$ \\
\hline TPV (mL) & $36.8 \pm 14.5$ & $68.3 \pm 17.1$ & $0.038^{*}$ \\
\hline TZV (mL) & $37.2 \pm 9.0$ & $46.1 \pm 14.6$ & $0.047^{\star}$ \\
\hline TZI & $0.48 \pm 0.11$ & $0.59 \pm 0.15$ & $0.063^{*}$ \\
\hline Resection time (min) & $48.7 \pm 10.1$ & $61.6 \pm 11.7$ & $0.051^{*}$ \\
\hline \multirow[t]{3}{*}{ Resected gland weight (g) } & $39.2 \pm 6.8$ & $48.3 \pm 7.7$ & $0.030^{*}$ \\
\hline & \multicolumn{3}{|c|}{ US } \\
\hline & With & Without & P-value \\
\hline$N(\%)$ & $29(7.8)$ & $344(92.2)$ & \\
\hline Resection speed (g/min) & $0.75 \pm 0.13$ & $0.84 \pm 0.19$ & $0.041^{*}$ \\
\hline$\Delta \mathrm{Hb}(\mathrm{g} / \mathrm{dL})$ & $1.59 \pm 0.58$ & $1.53 \pm 0.46$ & $0.061^{*}$ \\
\hline$\triangle \mathrm{HCT}(\%)$ & $6.3 \pm 1.9$ & $5.9 \pm 1.4$ & $0.078^{*}$ \\
\hline Incidence of urethral mucosa rupture (n) & 7 & 41 & $0.059^{* *}$ \\
\hline Incidence of re-catheterization ( $\mathrm{n}$ ) & 4 & 19 & $0.092^{* *}$ \\
\hline Incidence of countinous infection (n) & 10 & 21 & $0.000^{* *}$ \\
\hline
\end{tabular}

Values are presented as mean \pm SD or number.

US = urethral stricture; $\mathbf{B N C}=$ bladder neck contracture; PSA = total prostate-specific antigen; IPSS = International Prostate Symptom Score; TPV = total prostate volume;

$\mathbf{T Z V}=$ transitional zone volume; $\mathbf{T Z I}$ = transitional zone index; $\mathbf{H b}=$ hemoglobin; $\mathbf{H C T}=$ hematocrit.

*Student's t-test; ${ }^{* *}$ chi-square test.

9.2\% (5). Meatal strictures usually occur because of an inappropriate relationship between the size of the instrument and the diameter of the urethral meatus, while bulbar strictures occur because insufficient isolation by the lubricant causes the monopolar current to leak. To avoid this complication, lubricant should be applied sufficiently in the urethra and along the outer sheath of resectoscope and reapplied in cases of longer resection time. High cutting current should be avoided and an internal urethrotomy must be performed before TURP if there are pre-existing meatal or urethral strictures (30).

In this cohort, 29 cases developed postoperative stricture. Urethral mucosa rupture has been found as independent risk factor of US, which is in accord with the fact that once urethral mucosal integrity is lost, there would be urine leakage underneath the epithelium and subsequently inflammation and scar formation $(31,32)$. Lower resection speed was another risk factor, perhaps due to its correlation with unfavorable surgical process including hemorrhage, poor vision, prolonged operative time, more fluid leakage/absorption 
Table 4 - Multiple stepwise forward logistic regression analysis of factors influencing the incidence of postoperative US and BNC.

\begin{tabular}{lccc}
\hline \multirow{2}{*}{ Parameters } & \multicolumn{3}{c}{ Incidence of US } \\
\cline { 2 - 4 } & OR $(95 \% \mathrm{Cl})$ & P-value & Cut-off value \\
\hline Resection speed $(\mathrm{g} / \mathrm{min})$ & $0.48(0.30-0.69)$ & $0.022^{*}$ & 0.78 \\
$\Delta \mathrm{Hb}$ & $2.08(0.65-3.41)$ & 0.495 & \\
$\Delta \mathrm{HCT}$ & $1.79(0.62-1.98)$ & 0.102 \\
Intraoperative mucosa rupture & $2.44(1.63-3.97)$ & $0.023^{*}$ \\
Postoperative re-catheterization & $2.67(0.58-2.80)$ & 0.761 \\
Postoperative countinous infection & $1.49(1.21-1.74)$ & $0.028^{*}$ & \\
\hline & & Incidence of BNC \\
\hline Serum total PSA & $3.22(0.38-6.51)$ & 0.291 & \\
Storage score & $2.51(1.37-3.66)$ & $0.028^{*}$ \\
TPV (mL) & $0.15(0.06-0.82)$ & $0.035^{*}$ \\
TZV & $0.54(0.33-1.76)$ & 0.132 \\
TZI & $0.53(0.30-1.68)$ & 0.157 \\
Resection time & $0.76(0.31-3.79)$ & 0.145 \\
Resected gland weight & $0.55(0.24-3.63)$ & 0.304 \\
\hline
\end{tabular}

US = urethral stricture; $\mathbf{B N C}=$ bladder neck contracture; $\mathbf{H b}=$ hemoglobin; $\mathbf{H C T}=$ hematocrit; $\mathbf{P S A}=$ total prostate-specific antigen; $\mathbf{T P V}=$ total prostate volume; $\mathbf{T Z V}=$ transitional zone volume; $\mathbf{T Z I}=$ transitional zone index. ${ }^{*} \mathrm{P}<0.05$.

Figure 1 - Odds ratio value of independent risk/protective factors about postoperative urethral stricture and bladder neck contracture.

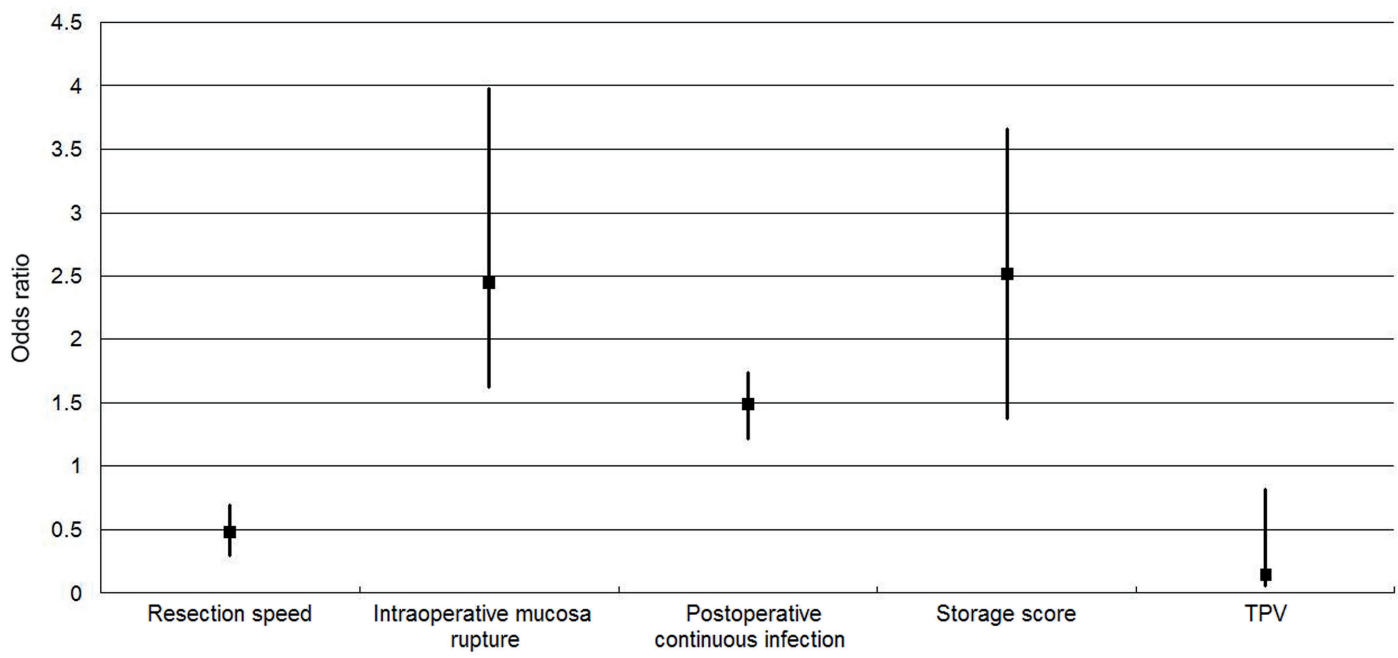


Figure 2 - The incidence (\%) of urethral stricture between patients with independent risk factors or not.

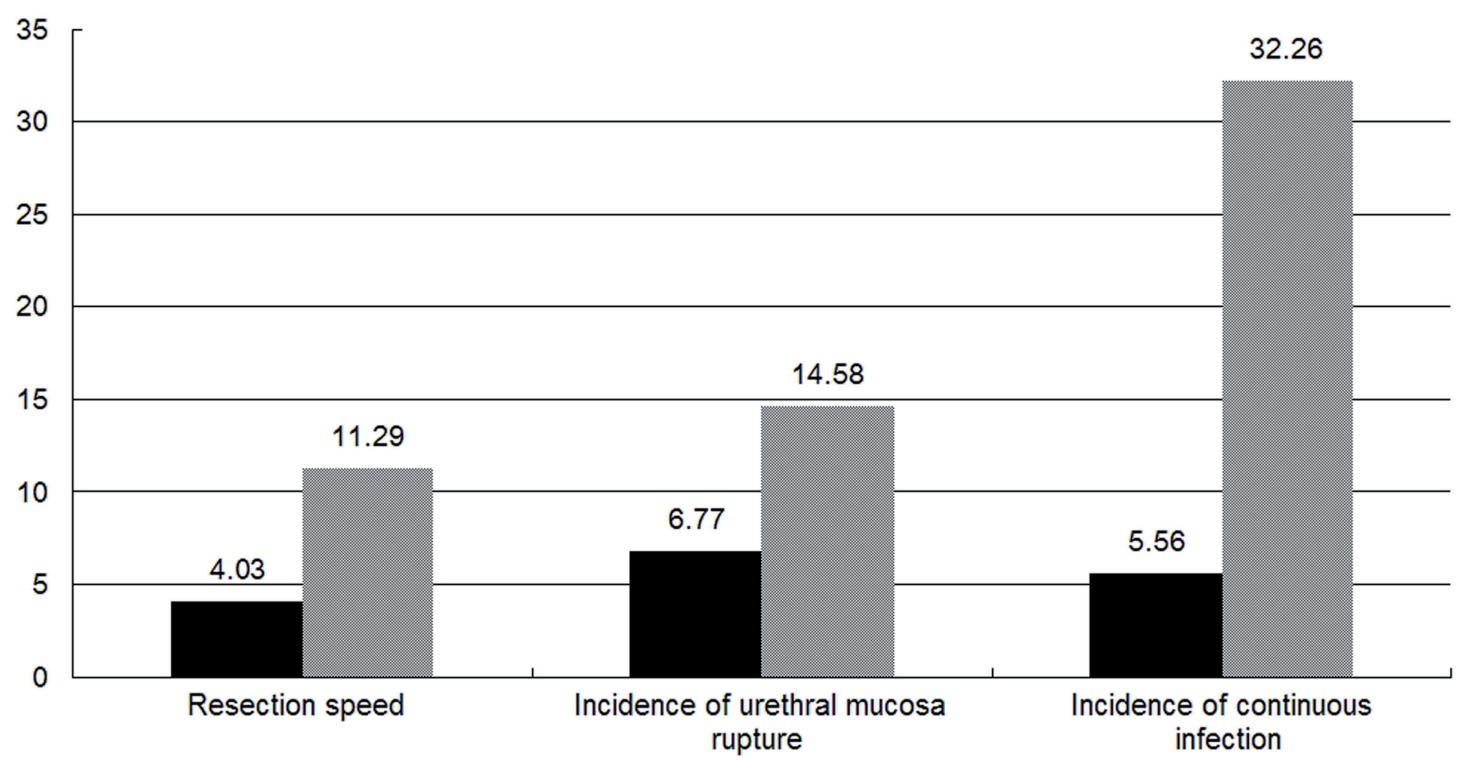

Figure 3 - The incidence (\%) of bladder neck contracture between patients with independent risk factors or not.

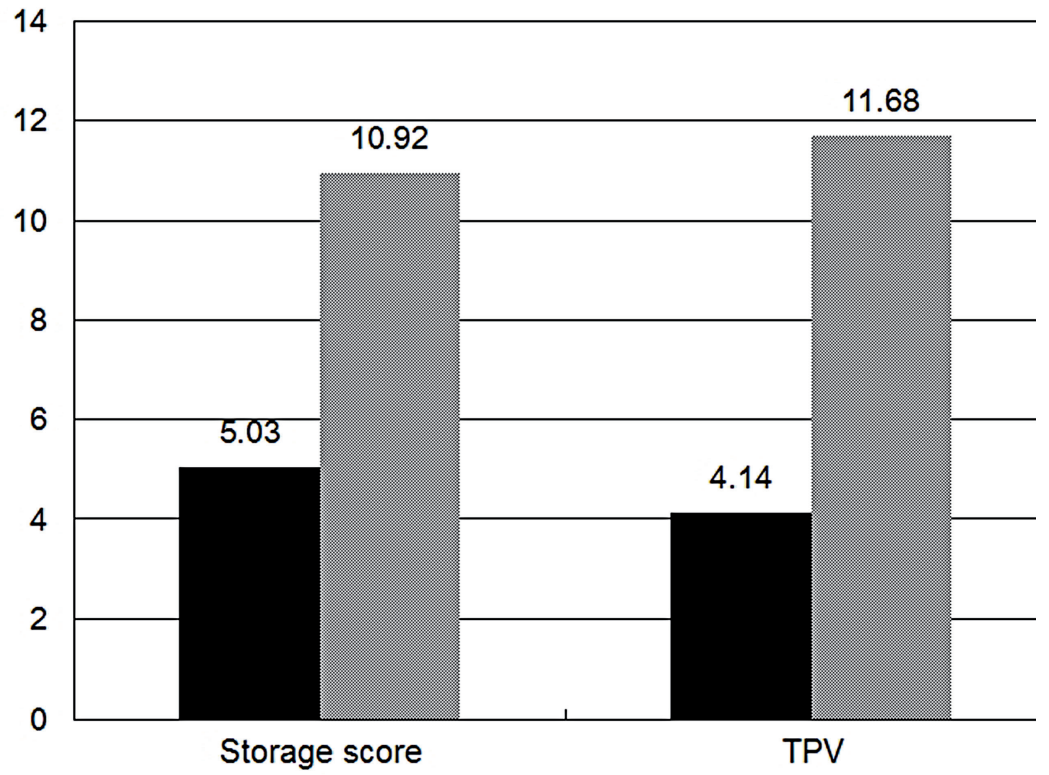


and urethral mucosal impairment, all of which are potential reasons of US. Because of a wound, former prostatic infection and continuous catheterization, there will always be a temporary local infection post-operation and after catheter removal. However, slowly wound healing, long-time clot retention as well as long-period catheterization etc. will probably lead to continuous infection and result in US. In this research, continuous infection was found as the last risk factor of US.

BNC usually happens after smaller glands are resected. Therefore, the indication for TURP in cases of smaller glands should be taken very seriously. A prophylactic bladder neck incision at the end of the procedure may reduce the incidence. Treatment includes electrical, or preferably, laser incision of the bladder neck (33). Except for lower TPV, we have found higher storage score another risk factor of BNC in this cohort, perhaps due to the negative correlation between storage score and B00I or TPV (data not shown).

In order to avoid potential bias caused by different surgeons, we have classified all patients into subgroups according to their operator. Not only perioperative parameters but also the incidence of US and BNC were found to have no difference between 3 subgroups (data not shown). However, this research still has limitations, especially on the small quantity of subjects and incidence of US and BNC. Further studies with larger samples and higher power are required to verify the result of this research.

\section{CONCLUSIONS}

Lower resection speed, intraoperative urethral mucosa rupture and postoperative continuous infection were associated with a higher risk of US while severer storage phase symptom and smaller prostate size were associated with a higher risk of BNC.

\section{ACKNOWLEDGMENTS}

The present study was funded by the research of "Prospective research about the efficacy of individualized treatment in LUTS/BPH patients" (project number: 134119A0600) and "Research of
SNPs in predicting the efficacy and progression of BPH patients receiving medication" (project number: 14430720800). Relevant personal from the department of urology, urodynamics and ultrasonography of Xin Hua Hospital have provided a great deal of help in the gathering of data.

\section{CONFLICT OF INTEREST}

None declared.

\section{REFERENCES}

1. Gilling PJ, Wilson LC, King CJ, Westenberg AM, Frampton $\mathrm{CM}$, Fraundorfer MR. Long-term results of a randomized trial comparing holmium laser enucleation of the prostate and transurethral resection of the prostate: results at 7 years. BJU Int. 2012;109:408-11.

2. Xue B, Zang Y, Zhang Y, Yang D, Gao J, Sun C, et al. GreenLight HPS 120-W laser vaporization versus transurethral resection of the prostate for treatment of benign prostatic hyperplasia: a prospective randomized trial. J Xray Sci Technol. 2013;21:125-32.

3. Tugcu V, Tasci Al, Sahin S, Zorluoglu F. Comparison of photoselective vaporization of the prostate and transurethral resection of the prostate: a prospective nonrandomized bicenter trial with 2-year follow-up. J Endourol. 2008;22:1519-25.

4. Mattiasson A, Wagrell L, Schelin S, Nordling J, Richthoff $J$, Magnusson B, et al. Five-year follow-up of feedback microwave thermotherapy versus TURP for clinical BPH: a prospective randomized multicenter study. Urology. 2007;69:91-6; discussion 96-7.

5. Rassweiler J, Teber D, Kuntz R, Hofmann R. Complications of transurethral resection of the prostate (TURP)-incidence, management, and prevention. Eur Urol. 2006;50:969-79; discussion 980.

6. Baazeem A, Elhilali MM. Surgical management of benign prostatic hyperplasia: current evidence. Nat Clin Pract Urol. 2008:5:540-9

7. Doluoglu OG, Gokkaya CS, Aktas BK, Oztekin CV, Bulut $S$, Memis $A$, et al. Impact of asymptomatic prostatitis on re-operations due to urethral stricture or bladder neck contracture developed after TUR-P. Int Urol Nephrol. 2012;44:1085-90.

8. Michielsen DP, Coomans D. Urethral strictures and bipolar transurethral resection in saline of the prostate: fact or fiction? J Endourol. 2010;24:1333-7.

9. Lee YH, Chiu AW, Huang JK. Comprehensive study of bladder neck contracture after transurethral resection of prostate. Urology. 2005;65:498-503;discussion 503. 
10. Ruszat R, Wyler SF, Seitz M, Lehmann K, Abe C, Bonkat G, et al Comparison of potassium-titanyl-phosphate laser vaporization of the prostate and transurethral resection of the prostate: update of a prospective non-randomized two-centre study. BJU Int. 2008;102:1432-8;discussion 1438-9.

11. Abrams P. Bladder outlet obstruction index, bladder contractility index and bladder voiding efficiency: three simple indices to define bladder voiding function. BJU Int. 1999;84:14-5.

12. Griffiths $D$, Höfner $K$, van Mastrigt $R$, Rollema $H J$, Spångberg $A$, Gleason D. Standardization of terminology of lower urinary tract function: pressure-flow studies of voiding, urethral resistance, and urethral obstruction. International Continence Society Subcommittee on Standardization of Terminology of PressureFlow Studies. Neurourol Urodyn. 1997;16:1-18.

13. Einarsson OJ, Lyrdal F, Neidhardt FO. The "shrinkage" of the prostate during transurethral resection. $\mathrm{Br} \mathrm{J}$ Urol. 1983;55:38-41.

14. Pastore AL, Mariani S, Barrese F, Palleschi G, Valentini AM, Pacini $L$, et al. Transurethral resection of prostate and the role of pharmacological treatment with dutasteride in decreasing surgical blood loss. J Endourol. 2013;27:68-70.

15. Mayer EK, Kroeze SG, Chopra S, Bottle A, Patel A. Examining the 'gold standard': a comparative critical analysis of three consecutive decades of monopolar transurethral resection of the prostate (TURP) outcomes. BJU Int. 2012;110:1595-601.

16. Park JK, Lee SK, Han SH, Kim SD, Choi KS, Kim MK. Is warm temperature necessary to prevent urethral stricture in combined transurethral resection and vaporization of prostate? Urology. 2009;74:125-9.

17. Holtgrewe HL, Valk WL. Factors influencing the mortality and morbidity of transurethral prostatectomy: a study of 2,015 cases. J Urol. 1962;87:450-9.

18. Madersbacher S, Lackner J, Brössner C, Röhlich M, Stancik I, Willinger M, et al. Prostate Study Group of the Austrian Society of Urology. Reoperation, myocardial infarction and mortality after transurethral and open prostatectomy: a nation-wide, long-term analysis of 23,123 cases. Eur Urol. 2005;47:499-504.

19. Elbahnasy AM, Farhat YA, Aboramadan AR, Taha MR. Percutaneous cystolithotripsy using self-retaining laparoscopic trocar for management of large bladder stones. J Endourol. 2010;24:2037-41.

20. Tascı Al, Ilbey YO, Tugcu V, Cicekler O, Cevik C, Zoroglu F. Transurethral resection of the prostate with monopolar resectoscope: single-surgeon experience and long-term results of after 3589 procedures. Urology. 2011;78:1151-5.

21. Thomas AW, Cannon A, Bartlett E, Ellis-Jones J, Abrams P. The natural history of lower urinary tract dysfunction in men: minimum 10-year urodynamic followup of transurethral resection of prostate for bladder outlet obstruction. J Urol. 2005;174:1887-91.
22. Hamann MF, Naumann CM, Seif C, van der Horst C, Jünemann KP, Braun PM. Functional outcome following photoselective vaporisation of the prostate (PVP): urodynamic findings within 12 months follow-up. Eur Urol. 2008;54:902-7.

23. Malek RS. GreenLight (TM) HPS Laser Therapy for BPH: Clinical Outcomes and Surgical Recommendations from the International GreenLight User (IGLU) Group. EurUrol Supp 2008;7:361-2.

24. Hill B, Belville W, Bruskewitz R, Issa M, Perez-Marrero R, Roehrborn C, et al. Transurethral needle ablation versus transurethral resection of the prostate for the treatment of symptomatic benign prostatic hyperplasia: 5-year results of a prospective, randomized, multicenter clinical trial. J Urol. 2004;171:2336-40.

25. Kuntz RM, Lehrich K, Ahyai SA. Holmium laser enucleation of the prostate versus open prostatectomy for prostates greater than 100 grams: 5-year follow-up results of a randomised clinical trial. Eur Urol. 2008 Jan;53(1):160-6.

26. Ruszat R, Wyler SF, Seitz M, Lehmann K, Abe C, Bonkat G, et al. Comparison of potassium-titanyl-phosphate laser vaporization of the prostate and transurethral resection of the prostate: update of a prospective non-randomized two-centre study. BJU Int. 2008;102:1432-8; discussion 1438-9.

27. Wendt-Nordahl G, Bucher B, Häcker A, Knoll T, Alken P, Michel MS. Improvement in mortality and morbidity in transurethral resection of the prostate over 17 years in a single center. $\mathrm{J}$ Endourol. 2007;21:1081-7.

28. Alhasan SU, Aji SA, Mohammed AZ, Malami S. Transurethral resection of the prostate in Northern Nigeria, problems and prospects. BMC Urol. 2008;8:18.

29. Das Bhagia S, Mahmud SM, El Khalid S. Is it necessary to remove foleys catheter late after transurethral prostatectomy in patients who presented with acute urinary retention secondary to benign prostatic hyperplasia? J Pak Med Assoc. 2010;60:739-41.

30. Faul P. Video TUR: raising the gold standard. New aspects, techniques and tendencies to minimize invasiveness. Eur Urol. 1993;24:256-61.

31. Scherz HC, Kaplan GW. Etiology, diagnosis, and management of urethral strictures in children. Urol Clin North Am. 1990;17:389-94.

32. Jørgensen PE, Weis N, Bruun E. Etiology of urethral stricture following transurethral prostatectomy. A retrospective study. Scand J Urol Nephrol. 1986;20:253-5.

33. Madersbacher S, Marberger M. Is transurethral resection of the prostate still justified? BJU Int. 1999;83:227-37.

Correspondence address: Huang Tao, MD

Anhui Provincial Hospital - Urology 17\#, Lujiang Rd Hefei Anhui 230001, China E-mail: dramantony@126.com 